Research Article

\title{
Temperature Field Variation Law of Low Exothermic Polymer Grouting Material in Repairing Void Damage of Frozen Soil Subgrade
}

\author{
Bei Zhang $\mathbb{D}^{1},{ }^{1}$ Baolin Wang, ${ }^{1}$ Yanhui Zhong $\mathbb{D},{ }^{1}$ Shuangjie Wang $\mathbb{D},{ }^{2}$ Xiaolong $\mathrm{Li}_{\mathbb{D}},{ }^{1}$ \\ and Shilun Wang 1 \\ ${ }^{1}$ School of Water Conservancy Engnieering, Zhengzhou University, Zhengzhou 450001, China \\ ${ }^{2}$ CCCC First Highway Consultants Co.,Ltd., Xi'an, China
}

Correspondence should be addressed to Yanhui Zhong; zhong_yanhui@163.com, Shuangjie Wang; wangshj@ccroad.com.cn, and Xiaolong Li; wennuandeshang@hotmail.com

Received 23 December 2020; Revised 21 January 2021; Accepted 25 February 2021; Published 27 March 2021

Academic Editor: Xiao Dong Zhao

Copyright (c) 2021 Bei Zhang et al. This is an open access article distributed under the Creative Commons Attribution License, which permits unrestricted use, distribution, and reproduction in any medium, provided the original work is properly cited.

In this study, the self-developed grouting mold was used to study the heat release characteristics of different density polymer grouting material under different temperature conditions. The spatial distribution characteristics of the frozen soil subgrade temperature field under the effect of polymer grouting repair were analyzed. Further, the rules governing the temperature change of a frozen soil subgrade monitoring point under the effect of polymer grouting repair were studied. The heat transfer mechanism of polymer grouting material in frozen soil subgrade was revealed. The results showed that in the void region of the frozen soil subgrade, a discontinuity zone appeared in the temperature field distribution isotherm due to the effect of voids; this zone exhibited a layered radioactive distribution along the two sides of the void area. Furthermore, during the exothermic stage of the curing reaction, the temperature distribution isotherms changed from a layered radioactive distribution to a ring distribution that decreased from the inside to outside. During the natural cooling process, the peripheral temperature of the ring isotherm first decreased and a negative temperature ring-shaped isotherm gradually formed. Finally, the upper boundary of the influence of the heat energy released by the curing reaction on the frozen soil subgrade temperature field was determined to be $30 \mathrm{~cm}$, and the lower boundary was $20 \mathrm{~cm}$.

\section{Introduction}

Permafrost accounts for $23 \%$ of the total land area in the world. At present, numerous highway projects have been built in permafrost regions [1-3]. As a road bearing foundation, frozen soil subgrade contains a large number of ice crystals with different structures. Uneven settlement occurs readily due to freeze-thaw effects and negatively impacts road traffic safety. In recent years, many scholars have studied the laws governing the temperature variation and stability of frozen soil subgrades. Yu et al. [4] studied the heat transfer characteristics of a sand-filled embankment using numerical simulation methods and revealed the rules governing the embankment temperature variations. Based on survey data, Han et al. [5] analyzed the degree of influence of factors such as subgrade height, pavement width, water content, and average annual temperature on the thermal stability of frozen subgrade. Zhang et al. $[6,7]$ monitored frozen soil subgrade temperatures for up to three years and proposed an empirical model that accounted for factors such as the average temperature, amplitude, and phase difference and analyzed the mechanism of subgrade frost heave development in detail. Liu et al. [8] conducted indoor water migration simulation experiments under freeze-thaw cycling and determined the mechanism of water migration during freezing. Current research supports the conclusion that, in areas of frozen soil, changes in the temperature field will cause frost heaving and thawing damage to the frozen soil subgrade, which is one of the primary causes of embankment instability. Chai et al. $[9,10]$ 
studied the microstructure of soils improved with cement and additives under constant loading and variable temperature conditions to determine how to improve the engineering properties of frozen soil and prevent uneven settlement. Mechanisms to improve frozen soil compressibility and thaw settlement performance were also revealed. Lvanov and Korotkov [11] used granular glass-ceramic foam material as an antifreeze layer and analyzed the principles of frozen soil subgrade temperature changes. Liu et al. [12] used numerical software to establish a model of the frozen soil subgrade of the Qinghai-Tibet Plateau to analyze the rules governing the deformation of the subgrade with and without loading. Zhang and Zhang [13] conducted an experimental study of the characteristics of moisture migration in frozen soil subgrades protected by gravel piles and concluded that gravel piles could effectively prevent the water level from rising, thereby controlling the soil freezing process and improving the bearing capacity of the subgrade. Based on field inspection data, Li et al. [14] analyzed the influence of gravel, ventilation, and the thermal insulation of the embankment on the temperature fields of frozen soil subgrades and revealed the embankment deformation characteristics of three soil layers. Huang et al. [15] used the unascertained measurement theory to establish a model to evaluate frozen soil subgrade stability and analyzed the effects of temperature stability on the subgrade.

In summary, previous research has primarily sought to improve frozen soil subgrade stability by adjusting the heat exchange conditions between the subgrade and the atmosphere, such that the internal temperature field would be in a balanced state. However, the thawed layer thicknesses of frozen soil continue to increase under the combined effects of climate warming and long-term vehicle loading. This can cause void damage due to uneven settlement and deformation of the frozen subgrade. Cement grouting is traditionally the primary method for repairing uneven subgrade settlement. Although the grout can fill loose areas of the subgrade and improve its strength, the material itself is not expansible and cannot raise the subsided pavement. Further, cement grouting requires a long construction period, resulting in traffic impacts due to construction traffic control.

In recent years, due to the expansibility of polymer grouting material, it quickly achieves design strength and can fill subgrade void regions and lift subsided pavement. Therefore, it is widely used to repair the uneven settlement deformation of subgrades. However, the heat energy released by the polymer curing reaction affects the internal temperature field of the frozen soil subgrade. Therefore, in this study, a self-developed grouting mold was used to study the heat release characteristics of polymer grouting material with different densities and different temperatures. Then, according to the engineering practice of nonuniform settlement of frozen soil subgrade, a numerical analysis model was established to study the temperature variation law of polymer grouting material in the process of filling frozen soil void and revealed the heat transfer mechanism of polymer grouting material in frozen soil subgrade. The results could provide theoretical support for the repair of the void damage caused by uneven settlement and the subgrade deformation of frozen soils.

\section{Analysis of Void Damage in Field Engineering}

Figure 1 shows the uneven settlement of frozen soil subgrade due to void damage. The roads constructed in frozen areas are primarily black asphalt pavement structures, which are more sensitive to the temperature field of the frozen soil subgrade. The black asphalt pavement increases the solar radiation absorption rate, which is converted into heat energy and is transferred downward such that the heat absorbed by the subgrade gradually increases. Further, the closed structure of the asphalt pavement hinders the process of heat dissipation from the subgrade surface, inhibiting the effective release of heat generated inside the subgrade and changing the equilibrium condition of the heat exchange between the frozen subgrade and the atmosphere.

Annually, the total heat absorbed by a frozen subgrade will be higher than the heat released due to the influence of seasonal temperature variations and the thermal conditions previously described. Therefore, the temperature inside the frozen soil subgrade is accumulatively increased, and some ice crystals melt into liquid water, forming a basin-shaped melting area inside the subgrade. Over time, this area gradually expands, and the tensile stress of the soil above it gradually increases. When the tensile stress is greater than the cohesive forces between the soil bodies, voiding damage occurs, leading to a significant reduction in the subgrade bearing capacity. Under the long-term effect of vehicle loads, the upper boundary of the void area simultaneously bears the weight of the soil above it and the compressive effect of vehicle loading, generating tensile stress in the horizontal direction. With the continued increase in tensile stress, longitudinal cracks will gradually appear in frozen soil subgrade, resulting in uneven settlement deformation damage. The continuous effect of the vehicle loads and the influence of rainfall and other atmospheric factors eventually results in slope instability and landslide, as shown in Figure 2.

\section{Material and Methods}

3.1. Polymer Grouting Material. Polyurethane polymer grouting material is mainly composed of polyisocyanate, polyether polyol, a foaming agent, a catalyst, a foam stabilizer, and various other additives. The exothermic curing reaction primarily consists of gel and foaming reactions [16-18]. The gel curing reaction occurs between the polyisocyanate - $\mathrm{NCO}$ groups and the polyol - $\mathrm{OH}$ groups; the foaming reaction results from the reaction of the polyisocyanate - $\mathrm{NCO}$ groups and $\mathrm{H}_{2} \mathrm{O}$ to form $\mathrm{CO}_{2}$ and urea. The reaction principle is shown in Figures 3 and 4.

\subsection{Test Equipment}

3.2.1. Grouting System. The vehicle-mounted polymer grouting integrated equipment used in the test mainly includes a pressure-supply device, a grouting pipe, a grouting 


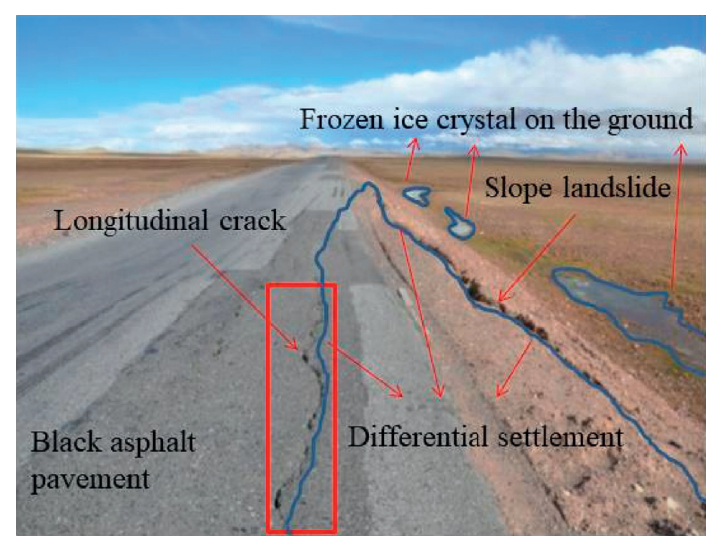

Figure 1: Typical damage resulting from a frozen soil subgrade.

gun, and a toolbox for cleaning the grouting equipment regularly. As shown in Figure 5, the self-developed grouting mold is shown in Figure 6. The inner diameter of the mold is $120 \mathrm{~mm}$, the outer diameter is $132 \mathrm{~mm}$, the height is $150 \mathrm{~mm}$, and the thickness of the flange plate is $20 \mathrm{~mm}$.

3.2.2. Data Monitoring Equipment. Figure 7 shows the data monitoring equipment used in the test. Data monitoring equipment includes temperature sensor, temperature collector, and data processing system. The measurement range of the temperature sensor is $-200^{\circ} \mathrm{C} \sim 300^{\circ} \mathrm{C}$, and the allowable error range is $\pm(0.15+0.002|t|)^{\circ} \mathrm{C}$. The data measured by the temperature sensor of the long probe are used to indicate the core temperature of the polymer grouting material, and the data measured by the short probe are used to indicate the surface temperature. The reaction temperature test in the curing stage of the polymer grouting material was carried out under the conditions of $-10^{\circ} \mathrm{C}, 0^{\circ} \mathrm{C}, 10^{\circ} \mathrm{C}$, $20^{\circ} \mathrm{C}$, and $30^{\circ} \mathrm{C}$.

\subsection{Numerical Analysis}

3.3.1. Numerical Model. According to the actual engineering damage profile shown in Figure 1, a typical area of frozen soil subgrade structure with a width of $10 \mathrm{~m}$ was selected to study the influence of polymer grouting material on the temperature field of the frozen soil subgrade. The roadway structure consisted of (from top to bottom) a $4 \mathrm{~cm} \mathrm{AC-13}$ SBR-modified asphalt upper layer, $5 \mathrm{~cm}$ AC-16 unmodified asphalt under layer, $8 \mathrm{~cm}$ cement-stabilized macadam base, $18 \mathrm{~cm}$ cement-stabilized gravel base, $20 \mathrm{~cm}$ graded gravel cushion, and $2.35 \mathrm{~m}$ gravelly soil fill. Below the ground surface, there were $1.5 \mathrm{~m}$ gravel soil, $2.5 \mathrm{~m}$ gravel and clay silt, and $6 \mathrm{~m}$ silty clay. In ABAQUS, a numerical model was established by first establishing components of different subgrade structural layers and then performing assembly operations. The resulting two-dimensional numerical analysis model is shown in Figure 8.

\subsubsection{Thermodynamic Parameters of Polymer Material.} Soil is a three-phase body composed of solid particles, liquid water, and gas. In frozen soil, part of the liquid water in the soil freezes into ice crystals (i.e., transforms into its solid phase) due to the influence of the low-temperature environment. Therefore, frozen soil is a multiphase medium composed of organic matter, solid particles, liquid water, ice, and gas. The gas content of frozen soil is relatively small; by ignoring the influence of gas on the specific heat capacity of the frozen soil, the specific heat capacity of the frozen and thawing soils can be defined according to the following formulas [19-23]:

$$
\begin{aligned}
C_{f} & =\frac{C_{d f}+\left(W-W_{u}\right) C_{i}+W_{u} C_{W}}{1+W}, \\
C_{u} & =\frac{C_{d u}+W C_{w}}{1+W} \rho,
\end{aligned}
$$

where $C_{u}$ and $C_{f}$ are the specific heat capacities of the melted and frozen soil, respectively; $C_{d u}$ and $C_{d f}$ are the specific heat capacities of the melting and frozen soil skeletons, respectively; $C_{i}$ and $C_{w}$ are the specific heat capacities of ice and water, respectively; $W$ and $W_{u}$ are the total and unfrozen water contents of the soil, respectively; and $\rho$ is the natural density of the frozen soil. In the temperature field simulation, the asphaltic surface layer material was taken to be a viscoelastic material, and the other layers were linear elastic materials. The road structure layers were assumed to be in complete contact, and the temperature and heat flow changes between the layers were assumed to be continuous and uninterrupted [24,25]. The thermal properties of each layer are shown in Tables 1 and 2 .

\subsubsection{Boundary Conditions}

(1) Solar Radiation Conditions. Solar radiation is the primary source of the earth's light and heat energy and causes the redistribution of the temperature field in a frozen soil subgrade. The daily variation in solar radiation $q(t)$ can be approximated using the following function [26-28]:

$$
q(t)=\left\{\begin{array}{l}
0, \quad 0 \leq t<12-\frac{c}{2}, 12+\frac{c}{2}<t \leq 24, \\
q_{0} \cos m w(t-12), \quad 12-\frac{c}{2} \leq t<12+\frac{c}{2},
\end{array}\right.
$$

where $q_{o}$ is the maximum radiation at noon, $q_{0}=0.131 \mathrm{mQ}$, where $m=12 / c$; $Q$ is the total solar radiation in one day, $\mathrm{J} /$ $\mathrm{m}^{2} ; c$ is the effective light hours, $h$; and $\omega$ is the angular frequency, rad.

Formula (3) is a piecewise function with jump discontinuities. Because the temperature field distribution in the frozen soil subgrade is continuous, Formula (3) can be expanded into a continuous cosine trigonometric form based on the principle of Fourier series correlation [29-32], as shown in Formula (4). In this calculation, the order $k$ can be set as 30 to meet engineering accuracy requirements.

$$
q(t)=\frac{a_{0}}{2}+\sum_{k=1}^{\infty} a_{k} \cos \frac{k \pi(t-12)}{12},
$$

where $a_{0}=\left(2 q_{o} / m \pi\right)$; 


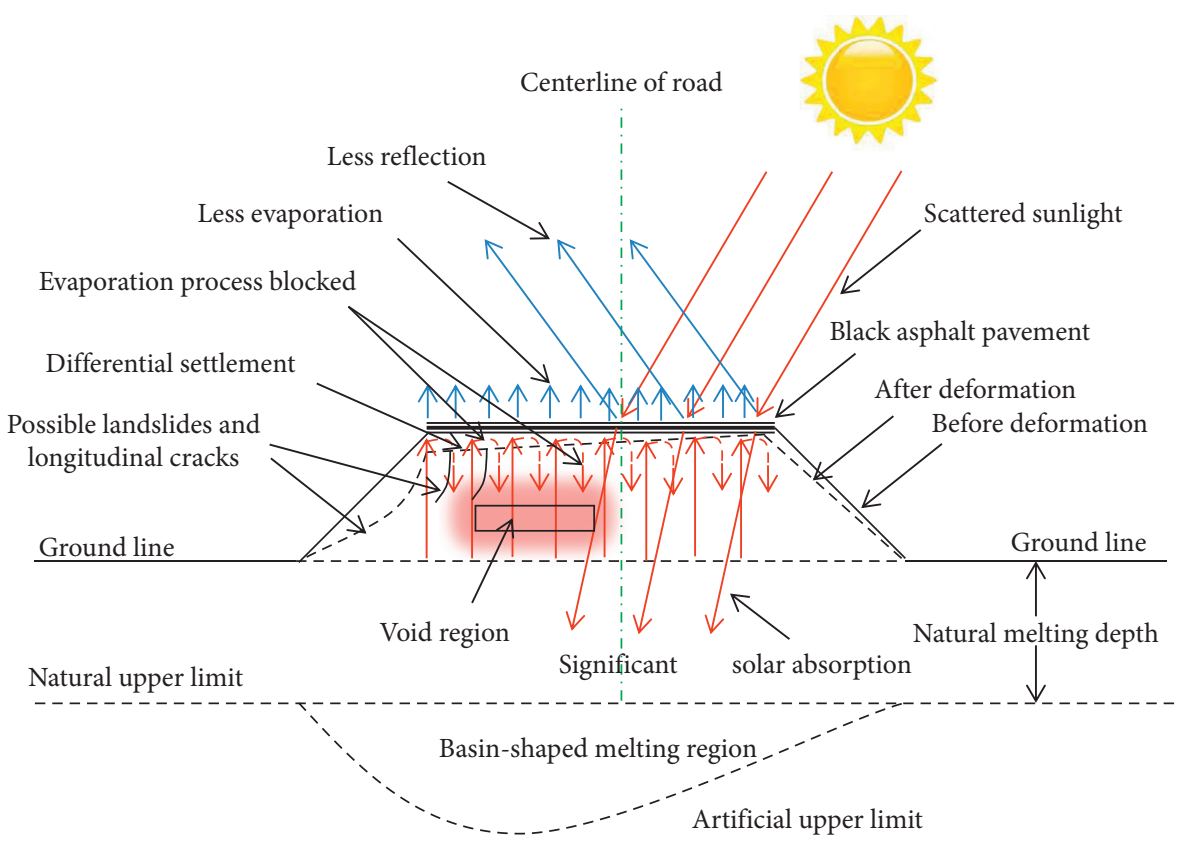

Figure 2: Mechanisms of the formation of uneven frozen soil subgrade settlement.

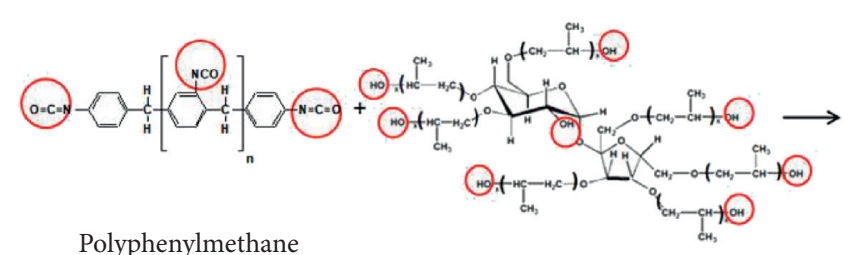

polyisocyanate

Sucrose polyether polyol

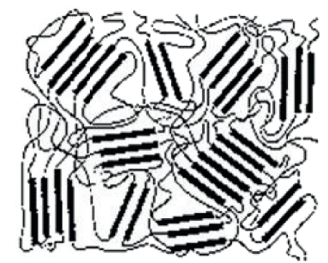

Polymer

$\mathrm{RNCO}+\mathrm{R}^{\prime} \mathrm{OH} \rightarrow \mathrm{RNHCOO} \mathrm{R}^{\prime}+$ thermal energy

FIgURE 3: Principle of gel reaction.

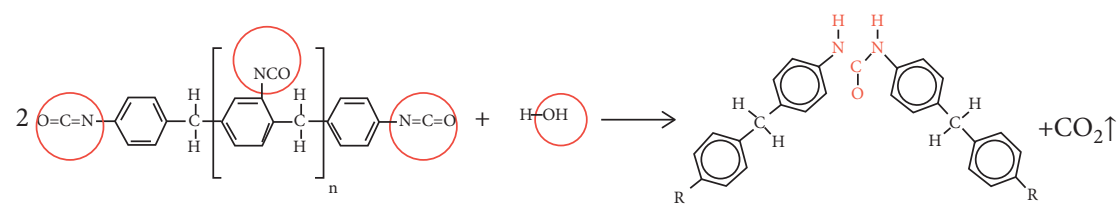

Polyphenylmethane polyisocyanate

$\mathrm{H}_{2} \mathrm{O}$

Urea

$\mathrm{CO}_{2}$ $2 \mathrm{RNCO}+\mathrm{H}_{2} \mathrm{O} \rightarrow \mathrm{RNHCONHR}+\mathrm{CO}_{2}+$ thermal energy

FIgURE 4: Principle of foaming reaction.

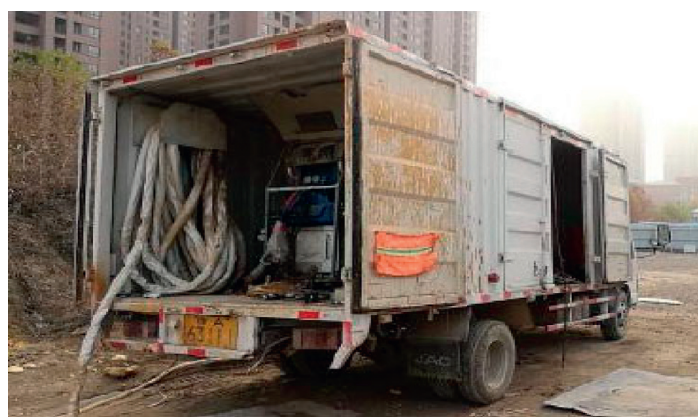

FIGURE 5: Vehicle-mounted polymer grouting integrated system. 

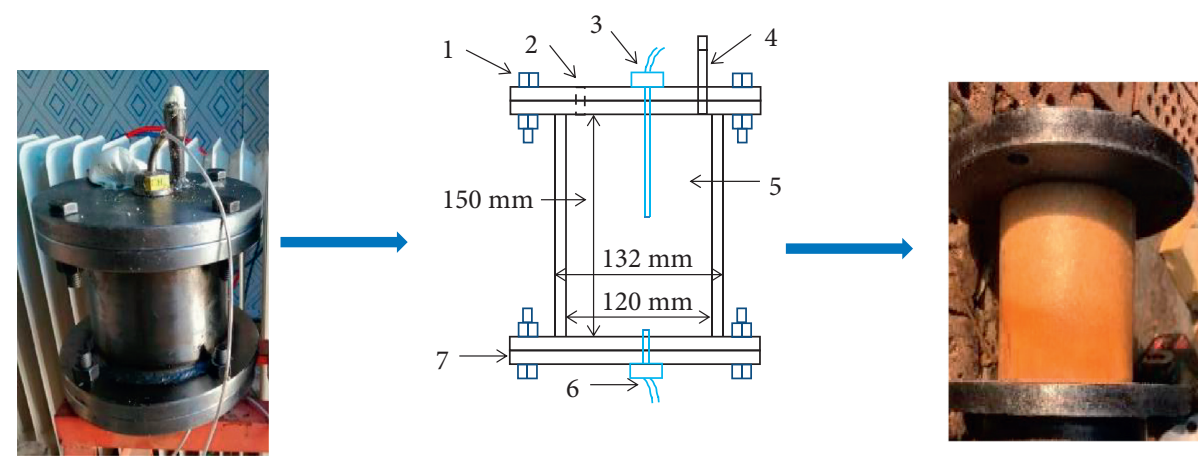

Figure 6: Grouting mold. (1) Bolt; (2) vent hole; $(3,6)$ temperature sensor; (4) grouting hole; (5) reaction vessel; (7) flange plate.

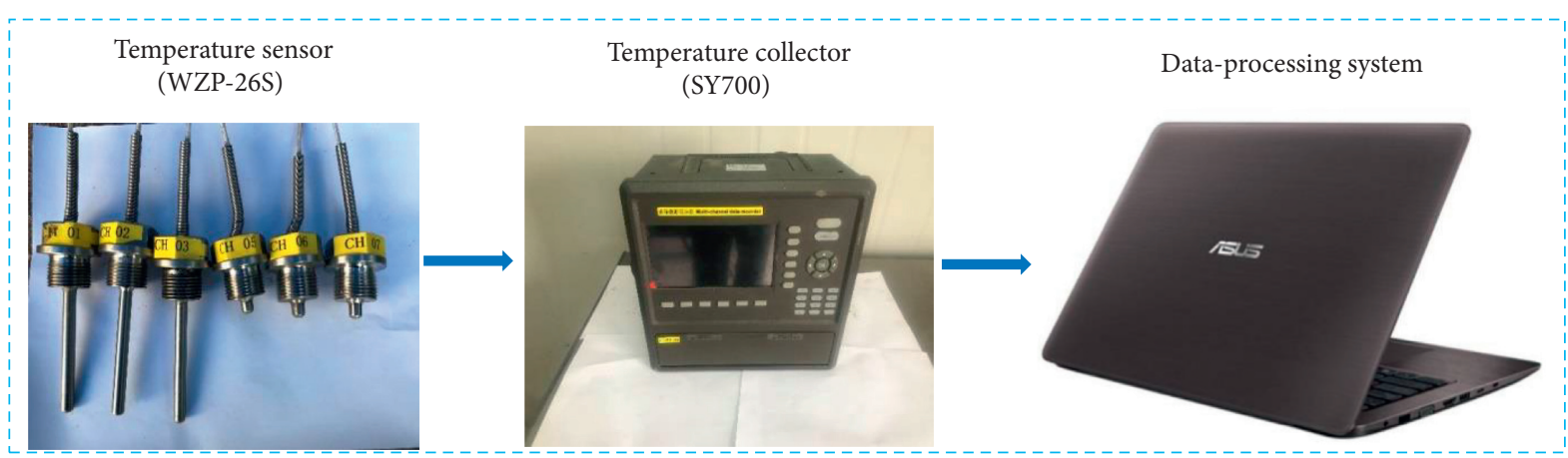

Figure 7: Data monitoring system.

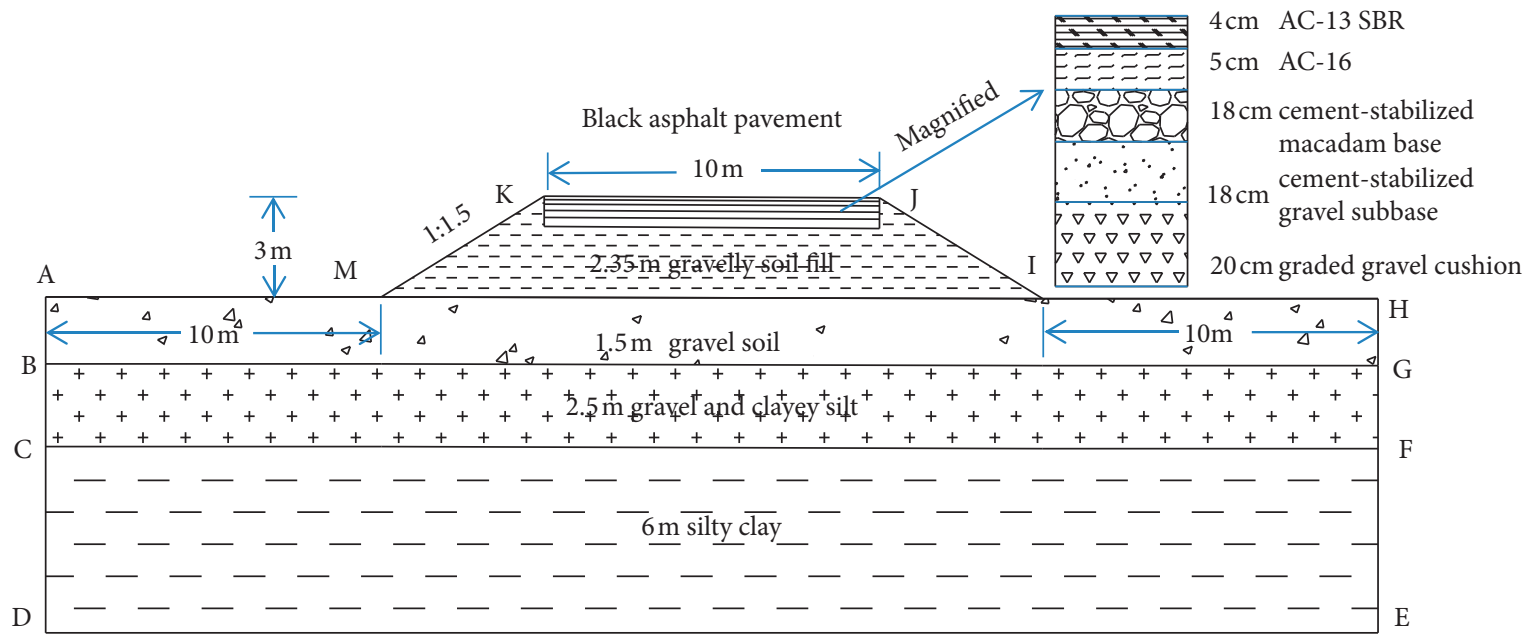

Figure 8: Two-dimensional numerical analysis model.

TABLE 1: Thermal properties of the subgrade materials.

\begin{tabular}{lccccc}
\hline Parameters & $\begin{array}{c}\text { AC-13 SBR-modified } \\
\text { asphalt }\end{array}$ & $\begin{array}{c}\text { AC-16 unmodified } \\
\text { asphalt }\end{array}$ & $\begin{array}{c}\text { Cement-stabilized } \\
\text { macadam }\end{array}$ & $\begin{array}{c}\text { Cement-stabilized } \\
\text { gravel }\end{array}$ & $\begin{array}{c}\text { Polymer grouting } \\
\text { material }\end{array}$ \\
\hline $\begin{array}{l}\text { Density } \rho\left(\mathrm{kg} / \mathrm{m}^{3}\right) \\
\begin{array}{l}\text { Specific heat capacity } C \\
\left(\mathrm{~J} /\left(\mathrm{kg} \cdot{ }^{\circ} \mathrm{C}\right)\right)\end{array}\end{array}$ & 2291 & 2316 & 2374 & 2340 & 250 \\
$\begin{array}{l}\text { Thermal conductivity } \lambda \\
\left(\mathrm{W} /\left(\mathrm{m} \cdot{ }^{\circ} \mathrm{C}\right)\right)\end{array}$ & 1124 & 917 & 1127 & 1141 & 1500 \\
\hline
\end{tabular}


TABle 2: Thermal material properties of the foundation.

\begin{tabular}{|c|c|c|c|c|}
\hline Parameters & Gravelly soil fill & Gravelly soil & Gravel and clay silt & Silty clay \\
\hline Density $\rho\left(\mathrm{kg} / \mathrm{m}^{3}\right)$ & 2000 & 2100 & 2340 & 2080 \\
\hline Specific heat capacity of frozen soil $C_{f}\left(\mathrm{~J} /\left(\mathrm{kg} \cdot{ }^{\circ} \mathrm{C}\right)\right)$ & 852 & 895 & 983 & 1200 \\
\hline Specific heat capacity of melted soil $C_{u}\left(\mathrm{~J} /\left(\mathrm{kg} \cdot{ }^{\circ} \mathrm{C}\right)\right)$ & 1020 & 996 & 1220 & 1370 \\
\hline Thermal conductivity of frozen soil $\lambda_{f}\left(\mathrm{~W} /\left(\mathrm{m} \cdot{ }^{\circ} \mathrm{C}\right)\right)$ & 1.985 & 2.26 & 1.32 & 1.85 \\
\hline Thermal conductivity of melted soil $\lambda_{u}\left(\mathrm{~W} /\left(\mathrm{m} \cdot{ }^{\circ} \mathrm{C}\right)\right)$ & 1.916 & 1.98 & 0.95 & 1.36 \\
\hline
\end{tabular}

$$
a_{k}=\left\{\begin{array}{l}
\frac{q_{0}}{\pi} \frac{1}{m+k} \sin (m+k) \frac{\pi}{2 m}+\frac{\pi}{2 m}, \quad k=m \\
\frac{q_{0}}{\pi} \frac{1}{m+k} \sin (m+k) \frac{\pi}{2 m}+\frac{1}{m-k} \sin (m-k) \frac{\pi}{2 m}, k \neq m .
\end{array}\right.
$$

(2) Temperature and Convection Heat Exchange Conditions. Under the influence of solar radiation, the atmospheric temperature changes periodically from day to night. In fewer than ten hours, the temperature changes from the daily minimum (approximately 04:00-06:00) to the daily maximum temperature (approximately 14:00), meaning that 14 or more hours are required to change from the highest to the lowest temperature [33]. Therefore, a linear combination of two sine functions is required to simulate the daily temperature change process, as shown in the following formula:

$$
T_{a}=\bar{T}_{a}+T_{m}\left[0.96 \sin \omega\left(t-t_{0}\right)+0.14 \sin 2 \omega\left(t-t_{0}\right)\right]
$$

where $\bar{T}_{a}$ is the average daily temperature; $T_{m}$ is the daily temperature change $T_{m}=(1 / 2)\left(T_{a}^{\max }-T_{a}^{\min }\right) ; T_{m}^{\max }$ and $T_{m}^{\mathrm{min}}$ are the daily maximum and minimum temperatures, respectively; $\omega$ is the angular frequency, $\omega=\pi / 12$, rad; and $t_{0}$ is the initial time. The time difference was set to be $2 \mathrm{~h}$ and $t_{0}=9 \mathrm{~h}$ to represent typical conditions.

Black asphalt pavement is exposed to the environment, and the wind speed affects the heat exchange between the pavement and the atmosphere. The relationship between the heat exchange coefficient $h_{c}$ and wind speed $V_{w}$ is linear.

$$
h_{c}=3.7 v_{w}+9.4 \text {, }
$$

where $h_{c}$ is the heat exchange coefficient and $V_{w}$ is the average daily wind speed, $\mathrm{m} / \mathrm{s}$.

(3) Pavement Effective Radiation Conditions. Black asphalt pavement increases the absorption rate of solar radiation $[34,35]$. Therefore, the boundary conditions of the effective ground radiation can be defined as

$$
q_{F}=\varepsilon \sigma\left[\left(\left.T_{1}\right|_{z=0}-T_{z}\right)^{4}-\left(T_{a}-T_{z}\right)^{4}\right],
$$

where $q_{F}$ is the effective radiation on the ground, $\mathrm{W} /\left(\mathrm{m}^{2} \cdot{ }^{\circ} \mathrm{C}\right)$; $\varepsilon$ is the emissivity (blackness) of the road surface, generally 0.81 for an asphalt road surface; $\sigma$ is the Stefan-Boltzmann constant (i.e., blackbody radiation constant), $2.014 e^{-4} \mathrm{~J} /$ $\left(\mathrm{m}^{2} \cdot \mathrm{h} \cdot \mathrm{K}^{4}\right) ;\left.T_{1}\right|_{z=0}$ is the road surface temperature, ${ }^{\circ} \mathrm{C} ; T_{a}$ is the atmospheric temperature, ${ }^{\circ} \mathrm{C}$; and $T_{z}$ is the absolute zero, ${ }^{\circ} \mathrm{C}, T_{z}=-273^{\circ} \mathrm{C}$. Statistical analyses and calculations were performed based on the relevant data obtained for the
TABLE 3: Boundary condition parameters.

\begin{tabular}{lc}
\hline Time & January \\
\hline Total daily solar radiation $\left(\mathrm{MJ} / \mathrm{m}^{2} \cdot \mathrm{d}^{-1}\right)$ & 10 \\
Solar radiation absorption rate & 0.9 \\
sDaily sunlight $(\mathrm{h})$ & 6.38 \\
Daily maximum temperature $\left({ }^{\circ} \mathrm{C}\right)$ & -8.4 \\
Daily minimum temperature $\left({ }^{\circ} \mathrm{C}\right)$ & -23.4 \\
Daily average temperature $\left({ }^{\circ} \mathrm{C}\right)$ & -16.7 \\
Daily average wind speed $(\mathrm{m} / \mathrm{s})$ & 5.17 \\
\hline
\end{tabular}

Qinghai-Tibet Plateau in January. The boundary condition parameters used in this study are shown in Table 3.

\section{Results and Analysis}

4.1. Law of Temperature Threshold Change. Figure 9 shows the change rule of the center and surface temperature threshold of the polymer grouting material in the mold grouting test. It can be seen from Figure 9 that the center temperature is significantly higher than the surface temperature. The central temperature and surface temperature threshold of polymer grouting materials increase with the increase in density. The increase in the center temperature is larger than that of the surface temperature. In addition, the threshold values of the center temperature and the surface temperature of the polymer grouting materials decrease with the decrease in the ambient temperature.

4.2. Simulation of the Heat Conduction Process. The numerical analysis model shown in Figure 8 was meshed in consideration of the calculation time and accuracy requirements. DC2D3 three-node linear heat transfer triangular elements were used for the slopes on both sides of the subgrade, and DC2D4 four-node linear heat transfer quadrilateral elements were used for the other structural layers. The numerical analysis model after meshing is shown in Figure 10. In the numerical analysis model, the solar radiation boundary conditions were defined using the Load module, by calling the DFLUX subroutine written in the Fortran computer language. The temperature and convection heat exchange boundary conditions were defined using the Interaction module, by calling the FILM subprograms, which were also written in Fortran. The surf radiation module defined the pavement effective radiation boundary conditions.

4.3. Initial Temperature Field. For this study, according to the core sample results obtained on the road, a rectangular void region of $200 \times 1 \mathrm{~cm}$ was set between the base layer and 


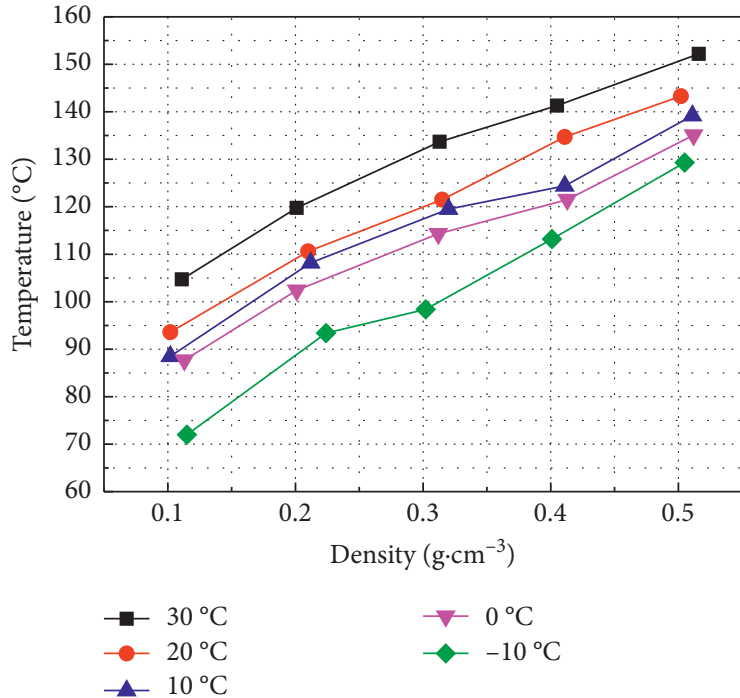

(a)

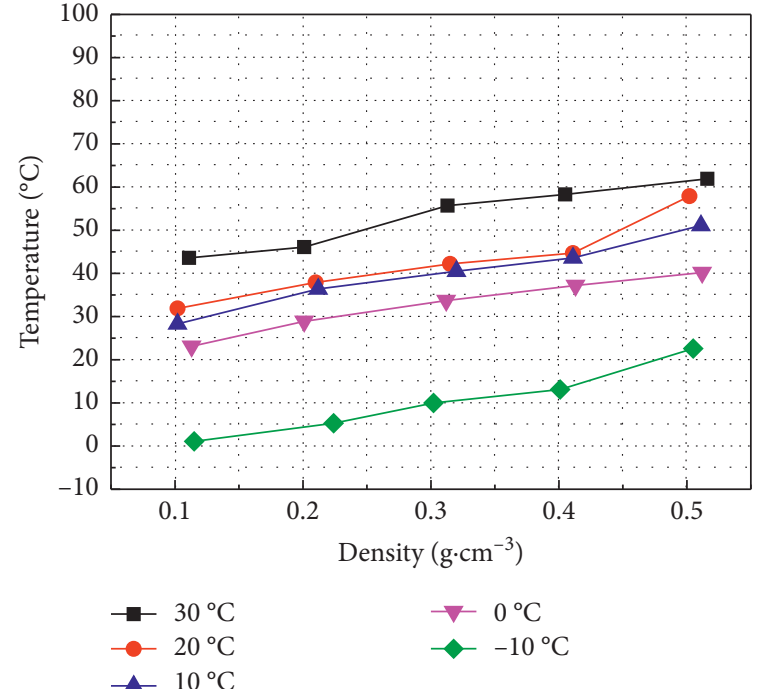

(b)

FIGURE 9: Temperature threshold of polymer grouting material: (a) central temperature and (b) surface temperature.

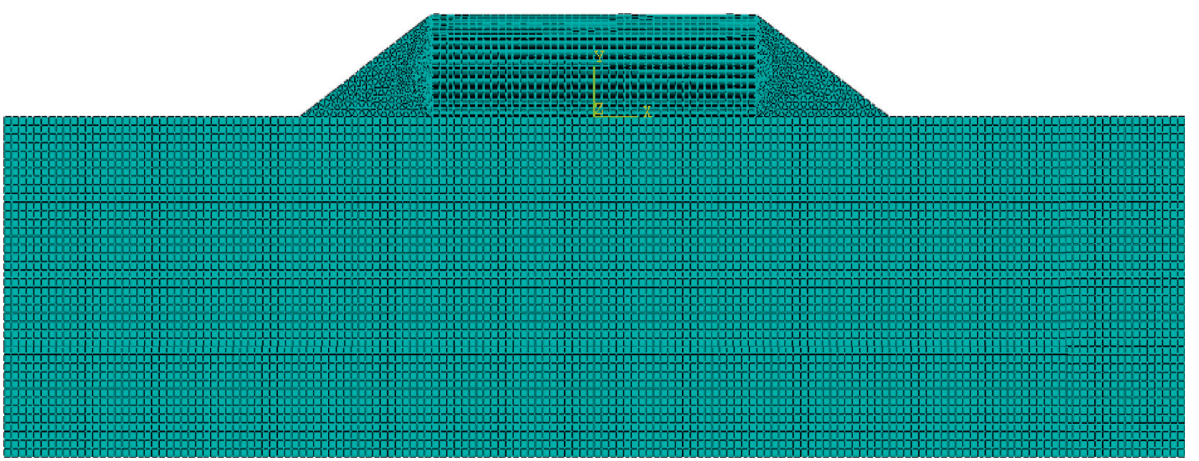

FIgURE 10: Meshing of the numerical model.

the cushion of the numerical model at a depth of $45 \mathrm{~cm}$ from the road surface. In the numerical model, input the thermal property parameters in Tables 1 and 2 into the corresponding structural layer materials. Then, the initial temperature field of subgrade was obtained by steady-state calculation. The initial temperature fields of the frozen soil subgrade models with and without void damage are shown in Figure 11.

Figure 11 shows that the initial temperature field distribution of the two subgrade types had similarities and differences. The minimum temperature of the ground surface of both subgrades was $-15^{\circ} \mathrm{C}$. As the depth increased, the temperature of the subgrade gradually increased, reaching the maximum temperature of $6^{\circ} \mathrm{C}$ at $0.5 \mathrm{~m}$ below the ground surface. The temperature of the subgrade then decreased gradually with depth, and the entire model had a continuous layered distribution characteristic. In contrast, under the influence of the void effects, the temperature field distribution isotherm displayed a discontinuity zone in the void region of the frozen soil subgrade and presented radioactive distribution characteristics along both sides of the void region. These observations are explained by the void region of the frozen subgrade being full of air. Due to the effect of the freeze-thaw cycle, the humidity of the air was relatively high, and its thermal conductivity was significantly different from that of the surrounding soil. Therefore, the heat conduction process in the void region had a discontinuity, ultimately leading to a discontinuous temperature distribution curve in this area.

4.4. Frozen Soil Subgrade Temperature Field Spatial Distribution Characteristics during Polymer Grouting Repair. Figures 12-14 show the temperature field spatial distribution characteristics under the effect of the polymer grouting repair. Figure 12 shows that the temperature threshold of the polymer grouting material in the void region of the frozen soil subgrade could be as high as $90^{\circ} \mathrm{C}$. The curing reaction of the polymer grouting material released heat energy, which caused the temperature of the subgrade near the void region filled by the grout to increase continuously and resulted in the observed ring-shaped 


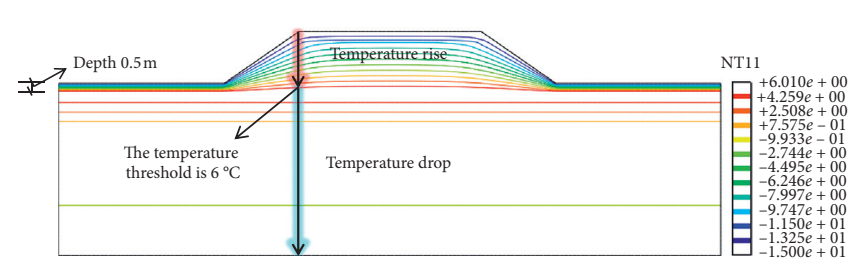

(a)

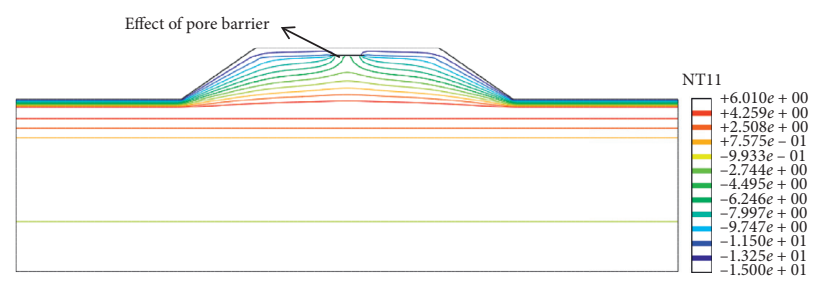

(b)

FIgURE 11: Initial temperature field distribution (a) without void damage and (b) with void damage.

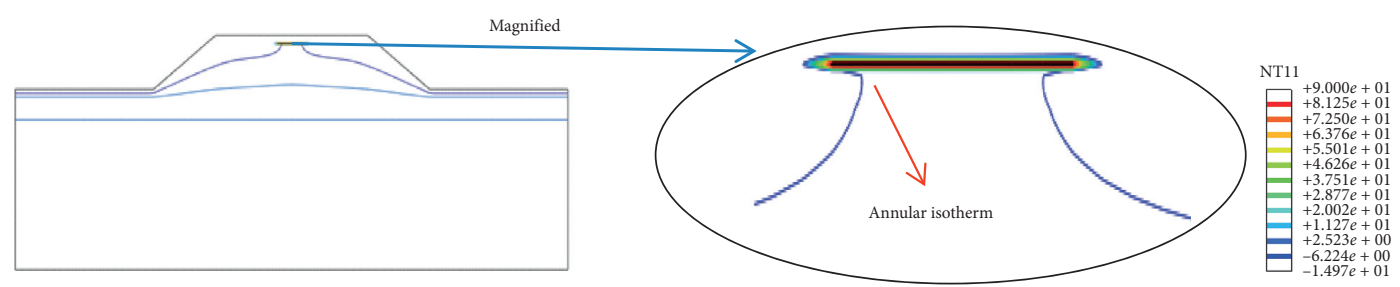

FIGURE 12: Temperature field distribution characteristics of the polymer grouting material at the maximum central temperature.

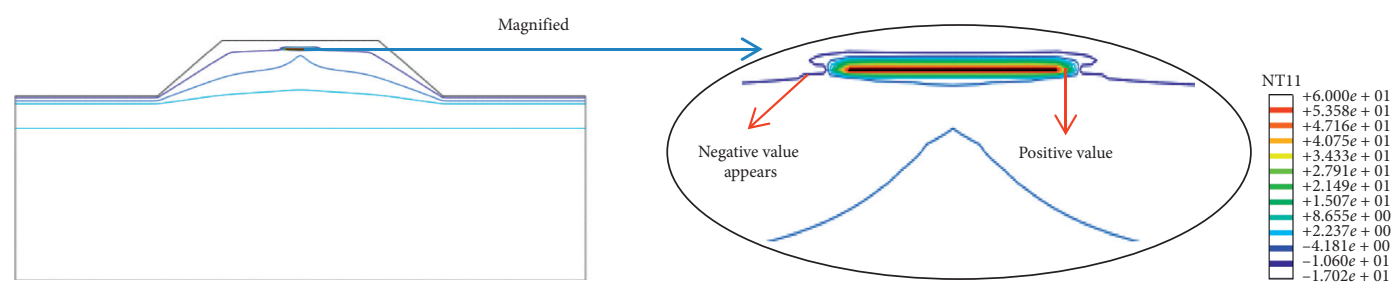

FIGURE 13: Temperature distribution characteristics of the polymer grouting material when the central temperature decreased to $60^{\circ} \mathrm{C}$.

isothermal distribution. The temperature decreased from $81.25^{\circ} \mathrm{C}$ to $2.52^{\circ} \mathrm{C}$ from inside to outside the modeled structure. Figure 13 shows that when the central temperature of the polymer grouting material decreased to $60^{\circ} \mathrm{C}$, the temperature threshold of the subgrade around the grout-filled void region decreased from $81.25^{\circ} \mathrm{C}$ to $53.58^{\circ} \mathrm{C}$. The temperature of the annular isotherm decreased from $53.58^{\circ} \mathrm{C}$ to $-4.18^{\circ} \mathrm{C}$ from the inside to the outside, at which time the temperature of the subgrade around the void region was negative, but the ring isotherm remained positive. As shown in Figure 14, when the central temperature of the polymer grouting material decreased to $14^{\circ} \mathrm{C}$, the temperature threshold of the subgrade around the grout-filled void region was only $11.75^{\circ} \mathrm{C}$, which was $86 \%$ lower than the maximum temperature of $81.25^{\circ} \mathrm{C}$. The temperature of the annular isotherm decreased from $11.75^{\circ} \mathrm{C}$ to $-9.33^{\circ} \mathrm{C}$ from inside to outside; concurrently, negative values appeared around the outer ring isotherm, and negative temperature isotherms formed.

Analysis of the spatial distribution characteristics of this temperature field revealed that the temperature of the frozen soil subgrade around the void region increased continuously due to the release of heat energy from the curing reaction. The ice crystals absorbed the heat, melted into liquid water, and absorbed the heat transferred from the polymer grouting material to the surrounding areas. This led to the isotherm around the void region changing from a layered radioactive distribution to a ring distribution that decreased from inside to outside. Locations further from the void region were less affected by the release of heat energy caused by the grout curing. Radioactive isotherms remained around the annular temperature field. The center temperature of the polymer grouting material began to gradually decrease after reaching its maximum due to the effects of the ambient temperature. During this process, the temperature of the outermost layer of the ring-shaped isotherm first began to decrease and then gradually formed a ring-shaped negative temperature isotherm. As the cooling process continued, the range of influence of the thermal energy released by the grout curing on the subgrade temperature field decreased further.

4.5. Time-Varying Temperature Changes in the Monitoring Points of the Frozen Subgrade during Grouting. In the numerical analysis model of frozen soil subgrade, 13 temperature monitoring points with an interval of $2.5 \mathrm{~cm}$ were evenly arranged above the center of the void region, and nine temperature monitoring points with an interval of $2.5 \mathrm{~cm}$ were evenly arranged below the center of the void region. Figures 15 and 16 show the temperature changes of the monitoring points with time. It can be seen from Figure 15 that the temperatures of the monitoring points located at $0.0 \mathrm{~cm}, 2.5 \mathrm{~cm}, 5.0 \mathrm{~cm}, 7.5 \mathrm{~cm}, 10.0 \mathrm{~cm}, 12.5 \mathrm{~cm}$, and $15 \mathrm{~cm}$ above the center of the frozen soil subgrade void region were significantly affected by the heat energy released by the 


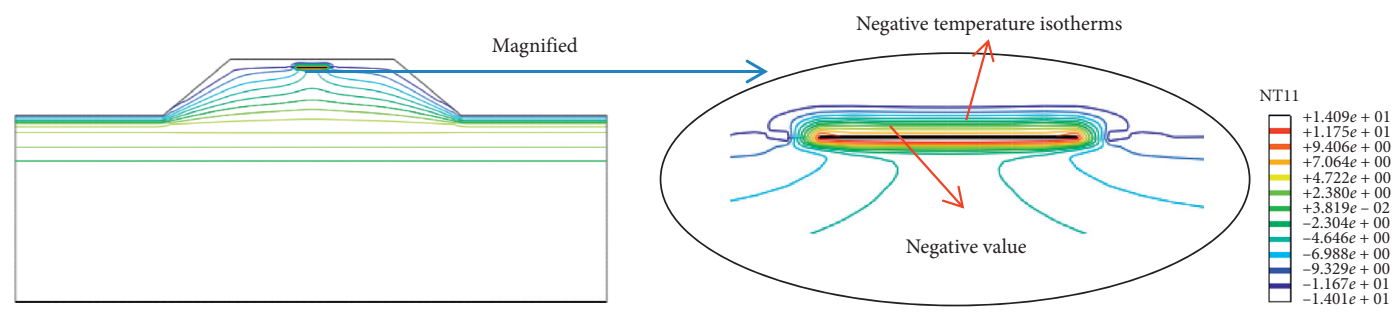

FIGURE 14: Temperature field distribution characteristics of the polymer grouting material when the central temperature decreased to $14^{\circ} \mathrm{C}$.

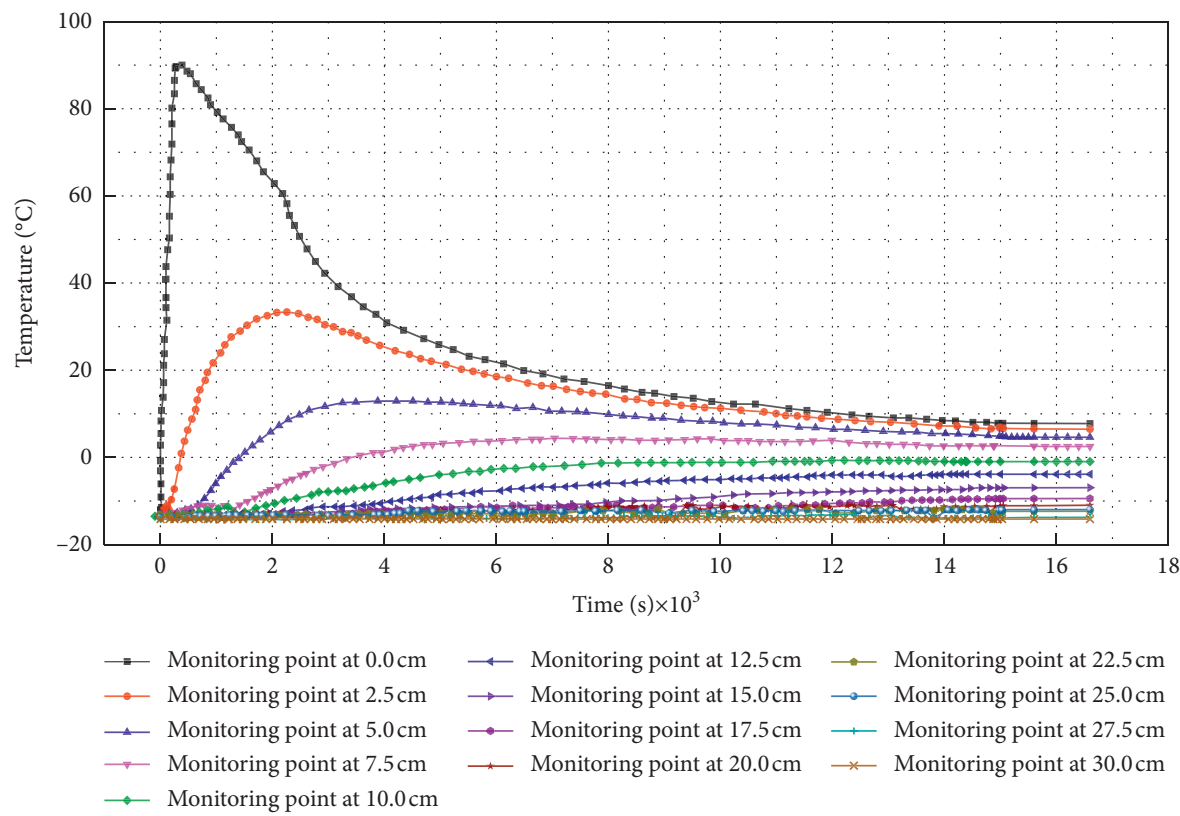

FIGURE 15: Temperature change over time at the monitoring points above the center of the frozen soil subgrade void region.

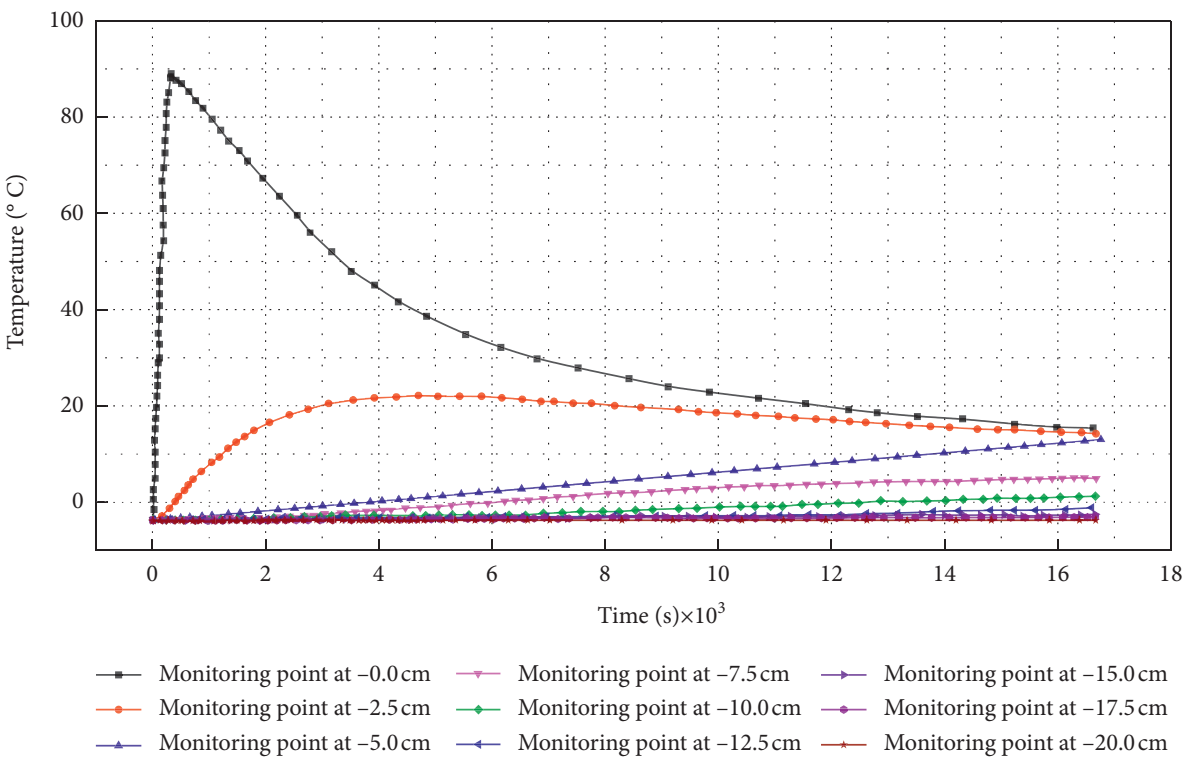

Figure 16: Temperature change over time at the monitoring points below the center of the frozen soil subgrade void region. 
polymer grouting material. Among them, the temperature change was the largest at the monitoring point at $0.0 \mathrm{~cm}$, rising to $89.5^{\circ} \mathrm{C}$ relatively quickly, while the highest temperature at the monitoring point at $2.5 \mathrm{~cm}$ was only $32.5^{\circ} \mathrm{C}$. The temperature changes of the other six monitoring points were less affected by the heat released by the polymer. Among them, the temperature of the monitoring point at $30 \mathrm{~cm}$ was essentially unchanged. Figure 16 shows that the temperatures of the monitoring points located at $-0.0 \mathrm{~cm}$, $-2.5 \mathrm{~cm},-5.0 \mathrm{~cm}$, and $-7.5 \mathrm{~cm}$ under the center of the void region were substantially impacted by the heat energy released by the polymer grouting material. Among them, the temperature of the monitoring point at $0.0 \mathrm{~cm}$ rose rapidly to $89.2^{\circ} \mathrm{C}$, while the highest temperature of the monitoring point at $-2.5 \mathrm{~cm}$ was only $21.5^{\circ} \mathrm{C}$. The temperature changes of the other five monitoring points were less affected by the heat released by the polymer, and the temperature of the monitoring point at $-20 \mathrm{~cm}$ was relatively unchanged.

Comparing Figures 12 and 13 shows that the monitoring points at $0.0 \mathrm{~cm}$ and $-0.0 \mathrm{~cm}$ were located on the critical planes of the upper and lower sides of the void region of the frozen subgrade, respectively. Therefore, the maximum temperature of the two monitoring points was consistent with the temperature threshold of the curing reaction. The temperature threshold of the monitoring point at $2.5 \mathrm{~cm}$ was $32.5^{\circ} \mathrm{C}$, which is $11^{\circ} \mathrm{C}$ higher than the $21.5^{\circ} \mathrm{C}$ observed at $-2.5 \mathrm{~cm}$. Comparing the monitoring point temperatures over time reveals that the temperature of the frozen soil subgrade located above the void region changed drastically due to the effect of the heat energy released by the polymer grouting material. The temperature at the monitoring points at $30 \mathrm{~cm}$ and $-20 \mathrm{~cm}$ remained virtually unchanged. Therefore, the upper and lower boundaries of the influence range of the heat release reaction could be considered to be $30 \mathrm{~cm}$ and $20 \mathrm{~cm}$, respectively.

\section{Conclusions}

In this study, firstly, the influence of void damage on the temperature field of frozen soil subgrade was analyzed. Then, the heat transfer characteristics between polymer grouting material polymerization heat release and frozen soil subgrade were studied. Finally, the influence range of polymer grouting material polymerization heat release on the temperature field of frozen soil roadbed was clarified. The conclusions are as follows:

(1) The temperature field inside the frozen soil subgrade had a continuous layered distribution. However, in the void region, the temperature field distribution isotherm was interrupted by a gap, and a discontinuity zone appeared in the void region, revealing the characteristics of the distribution of radioactivity along the two sides of the void region.

(2) During the exothermic curing reaction of the polymer grouting material, the temperature of the frozen soil subgrade around the void region continuously increased due to the release of heat energy. Spatially, the distribution of isotherms changed from a layered radioactive distribution to a ring distribution that decreased from inside to outside. During the natural cooling process, the peripheral temperature of the ring isotherm first decreased and a negative temperature ring isotherm gradually formed.

(3) The temperature of the frozen soil subgrade above the void region was greatly affected by the heat energy released by the polymer grouting material, and the rate of temperature change was greater than for the measurement points below the void region. The upper boundary of the influence range of the thermal energy released by the polymer grouting material on the subgrade temperature field was $30 \mathrm{~cm}$, and the lower boundary was $20 \mathrm{~cm}$.

\section{Data Availability}

The data used to support the findings of this study are available from the corresponding author upon request.

\section{Conflicts of Interest}

The authors declare that they have no conflicts of interest in this work.

\section{Acknowledgments}

The authors acknowledge the support received from the National Key Research and Development Plan (grant no. 2018YFB1600200), National Natural Science Foundation of China (grant nos. 51878622 and 51878624), Major Scientific and Technological Special Project in Henan (grant no. 181100310400), Henan Science Fund for Distinguished Young Scholars (grant no. 202300410354), Program for Science and Technology Innovation Talents in Universities of Henan Province (grant no. 19HASTIT041), Key Research Projects of Higher Education in Henan Province (grant no. 18A580001), and Science and Technology R\&D Project (grant no. 2017-ZJKJ-PTJS03).

\section{References}

[1] S. J. Wang, Z. Wang, and J. B. Chen, Expressway Layout and Permafrost Environment Coupling in Permafrost Regions of Qinghai Tibet Plateau, pp. 2-10, Shanghai Scientific \& Technical Publishers, Shanghai, China, 2019.

[2] M. Chai, H. Zhang, J. Zhang, and Z. Zhang, "Effect of cement additives on unconfined compressive strength of warm and ice-rich frozen soil," Construction and Building Materials, vol. 149, pp. 861-868, 2017.

[3] H. Li, N. Fang, X. Wang, C. Wu, and Y. Fang, "Evaluation of the coordination of structural layers in the design of asphalt pavement," Applied Sciences, vol. 10, no. 9, p. 3178, 2020.

[4] W. B. Yu, H. Da, F. L. Han et al., "Heat transfer characteristics of sand-filled embankment in permafrost regions of Tibetan plateau," Arabian Journal for Science And Engineering, vol. 45, no. 5, pp. 3683-3693, 2019.

[5] F. Han, W. Yu, X. Zhang, F. Yu, X. Yi, and D. Hu, "Parameter sensitivity analyses of influence on thermal regime of embankment in Permafrost Regions along the Qinghai-Tibet 
Engineering Corridor," Cold Regions Science and Technology, vol. 166, p. 102817, 2019.

[6] Y.-Z. Zhang, Y.-L. Du, and B.-C. Sun, "Temperature distribution analysis of high-speed railway roadbed in seasonally frozen regions based on empirical model," Cold Regions Science And Technology, vol. 114, pp. 61-72, 2015.

[7] Y. Z. Zhang, Y. L. Du, and B. C. Sun, "Roadbed deformation characteristics of roadbed-bridge transition section for high speed railway in seasonal frozen soil region," China Railway Science, vol. 37, no. 1, pp. 39-45, 2016.

[8] L. Q. Liu, X. S. Mao, Q. Wu et al., "Mechanism of groundwater migration in the subgrade in a seasonally frozen soil area," Journal of Cold Regions Engineering, vol. 33, no. 4, Article ID 06019001, 2019.

[9] M. Chai and J. Zhang, "Improvement of compressibility and thaw-settlement properties of warm and ice-rich frozen soil with cement and additives," Materials, vol. 12, no. 7, p. 1068, 2019.

[10] M. Chai, J. Zhang, W. Ma, Z. Yin, Y. Mu, and H. Zhang, "Thermal influences of stabilization on warm and ice-rich permafrost with cement: field observation and numerical simulation," Applied Thermal Engineering, vol. 148, pp. 536543, 2019.

[11] K. S. Lvanov and E. A. Korotkov, "Investigation of the effect of a layer of granulated foam-glass ceramic on the temperature conditions of frozen soil," Soil Mechanics and Foundation Engineering, vol. 54, no. 5, pp. 349-355, 2017.

[12] X. H. Liu, J. Q. Jia, and Y. B. Zhang, "Simulation analysis of the long-term stability for frozen soil roadbed," Mathematical Problems in Engineering, vol. 20147 pages, Article ID 605890, 2014.

[13] S. G. Zhang and Z. Zhang, "The experimental research of transverse gravel pile preventing roadbed freezing," in Proceedings of the 2011 International Conference on Multimedia Technology, pp. 1300-1302, IEEE, Hangzhou, China, July 2011.

[14] J. Liu, B. Tai, and J. Fang, "Ground temperature and deformation analysis for an expressway embankment in warm permafrost regions of the Tibet plateau," Permafrost and Periglacial Processes, vol. 30, no. 3, pp. 208-221, 2019.

[15] C. Huang, Q. Li, S. Wu, and Y. Liu, "Subgrade stability evaluation in permafrost regions based on unascertained measurement model," Geotechnical and Geological Engineering, vol. 37, no. 2, pp. 707-719, 2019.

[16] H. Zhang, C. Su, X. Bu, Y. Zhang, Y. Gao, and M. Huang, "Laboratory investigation on the properties of polyurethane/ unsaturated polyester resin modified bituminous mixture," Construction and Building Materials, vol. 260, p. 119865, 2020.

[17] H. Fang, Y. Su, X. Du, F. Wang, and B. Li, "Experimental and numerical investigation on repairing effect of polymer grouting for settlement of high-speed railway unballasted track," Applied Sciences, vol. 9, no. 21, p. 4496, 2019.

[18] S. Saleh, N. Z. M. Yunus, K. Ahmad, and N. Ali, "Improving the strength of weak soil using polyurethane grouts: a review," Construction and Building Materials, vol. 202, pp. 738-752, 2019.

[19] R. Jia, Q. Xiong, G. Xu, K. Wang, and S. Liang, "A method for two-dimensional temperature field distribution reconstruction," Applied Thermal Engineering, vol. 111, pp. 961-967, 2017.

[20] Q. M. Meng, X. S. Mao, Y. S. Fan et al., "Numerical analysis of the effect of roadside accumulated water on subgrade temperature field in the freezing region," Applied Mechanics and Materials, vol. 470, pp. 284-288, 2014.
[21] Q. Yu, K. Fan, Y. You, L. Guo, and C. Yuan, "Comparative analysis of temperature variation characteristics of permafrost roadbeds with different widths," Cold Regions Science and Technology, vol. 117, pp. 12-18, 2015.

[22] Y. Zeng, K. Liu, X. Zhou, and L. Fan, "Tunnel temperature fields analysis under the couple effect of convection-conduction in cold regions," Applied Thermal Engineering, vol. 120, pp. 378-392, 2017.

[23] M. Mahedi, B. Cetin, and K. S. Cetin, "Freeze-thaw performance of phase change material (PCM) incorporated pavement subgrade soil," Construction and Building Materials, vol. 202, pp. 449-464, 2019.

[24] Z. W. Zhu and J. G. Ning, "Numerical analysis on thermal and stress coupling of soil subgrade," Applied Mechanics and Materials, vol. 29-32, pp. 107-111, 2010.

[25] Y. Sun, C. Du, H. Gong, Y. Li, and J. Chen, "Effect of temperature field on damage initiation in asphalt pavement: a microstructure-based multiscale finite element method," Mechanics of Materials, vol. 144, p. 103367, 2020.

[26] J. Y. Yuan, J. H. Cheng, C. F. Wang et al., "Analysis of heat conduction mechanism on tympanites roadbed," Advanced Materials Research, vol. 838, pp. 1286-1290, 2014.

[27] L. Jiang and S. Wang, "Enhancing heat release of asphalt pavement by a gradient heat conduction channel," Construction and Building Materials, vol. 230, p. 117018, 2020.

[28] A. Sha, Z. Liu, K. Tang, and P. Li, "Solar heating reflective coating layer (SHRCL) to cool the asphalt pavement surface," Construction and Building Materials, vol. 139, pp. 355-364, 2017.

[29] L. Cong, F. Yang, G. Guo, M. Ren, J. Shi, and L. Tan, “The use of polyurethane for asphalt pavement engineering applications: a state-of-the-art review," Construction and Building Materials, vol. 225, pp. 1012-1025, 2019.

[30] T. Wang, G. Zhou, J. Wang, and T. Chen, "Statistical characteristics and probabilistic analysis of uncertain settlement of subgrade in permafrost regions," Cold Regions Science and Technology, vol. 175, p. 103079, 2020.

[31] H. Liu, F. Niu, and H. Guan, "An engineering evaluation index of thermal asymmetry in subgrade and its optimal design in cold regions," Cold Regions Science and Technology, vol. 137, pp. 1-6, 2017.

[32] G. Cheng, Z. Sun, and F. Niu, "Application of the roadbed cooling approach in Qinghai-Tibet railway engineering," Cold Regions Science and Technology, vol. 53, no. 3, pp. 241-258, 2008.

[33] G. Cheng, Q. Wu, and W. Ma, "Innovative designs of permafrost roadbed for the Qinghai-Tibet Railway," Science in China Series E: Technological Sciences, vol. 52, no. 2, pp. 530-538, 2009.

[34] Z. Zhang, Q. Wu, Y. Liu, Z. Zhang, and G. Wu, "Thermal accumulation mechanism of asphalt pavement in permafrost regions of the Qinghai-Tibet Plateau," Applied Thermal Engineering, vol. 129, pp. 345-353, 2018.

[35] Z. Liu, W. Yang, and J. Wei, "Analysis of random temperature field for freeway with wide subgrade in cold regions," Cold Regions Science and Technology, vol. 106-107, pp. 22-27, 2014. 